\title{
Influence of Microwave Power on EPR Signal of Melanin Radical and Copper(II) Ions in DOPA-Melanin Complexes
}

\author{
L. NAjder-Kozdrowska ${ }^{a, *}$, B. Pilawa ${ }^{b}$, A.B. WięCKOWski ${ }^{a}$, E. Buszman $^{c}$ \\ AND D. WRZEŚNIOK ${ }^{c}$ \\ ${ }^{a}$ Division of Spectroscopy of Functional Materials, Institute of Physics, Faculty of Physics and Astronomy \\ University of Zielona Góra, Z. Szafrana 4a, 65-516 Zielona Góra, Poland \\ ${ }^{b}$ Department of Biophysics, School of Pharmacy, Medical University of Silesia, Sosnowiec, Poland \\ ${ }^{c}$ Department of Pharmaceutical Chemistry, School of Pharmacy, Medical University of Silesia, Sosnowiec, Poland \\ (Received November 26, 2012; in final form April 4, 2013) \\ Electron paramagnetic resonance spectroscopy EPR was used for examination of microwave saturation in \\ DOPA-melanin complexes with kanamycin and $\mathrm{Cu}$ (II) ions. The fast spin-lattice relaxation processes take place \\ in system of paramagnetic metal ions. EPR signal of melanin radical saturated with growing of microwave power \\ used during measurements. After adding $\mathrm{Cu}$ (II) ions a shortening of relaxation time is observed for EPR signal of \\ melanin radical.
}

DOI: $10.12693 /$ APhysPolA.124.112

PACS: 76.30.Rn, 87.80.Lg, 87.64.kh

\section{Introduction}

Melanin is a polymer very prevalent in nature $[1,2]$. Chemical and physical researches on melanin give information about its properties (affinity to drugs and metal ions, photoprotection) that are important for accurate working of living organisms [3, 4]. Interactions between melanin and drugs provided stirring radicals that have negative effects in pigmented tissues $[5,6]$. Melanin consists a high concentration of paramagnetic centers that make the using of electron paramagnetic resonance spectroscopy possible. Unpaired electrons are localized on oxygen atoms of indol-5,6-semiquinone groups with spin equal to $S=1 / 2[1,7]$.

In lower temperature besides paramagnetic centers with spin $S=1 / 2$, there exist biradical forms with spin $S=1$ [8]. The EPR method provides information about concentration of paramagnetic centers, about interaction spin-spin and spin-lattice, about surrounding of unpaired electrons, and shows changes in shape of EPR line under influence of drugs and metal ions (diaand paramagnetic) added to melanin. Line shape of EPR signal of melanin and changes in concentration of paramagnetic centers after adding kanamycin and $\mathrm{Cu}(\mathrm{II})$ ions was studied in paper [9]. In this work we present a complement of our study by the method of microwave saturation of DOPA-melanin complexes with kanamycin and copper(II) ions [9].

\section{Samples}

DOPA-melanin was obtained according to the procedure of Bins et al. [10]. 3,4-dihydroxyphenylalanine

*corresponding author; e-mail: lkozdrowska@wp.pl
(L-DOPA) was used as a precursor. As the ligand there were used kanamycin and copper(II) ions obtained from copper chloride $\mathrm{CuCl}_{2}$. For EPR study we used samples as follows: (DOPA-melanin)-kanamycin, (DOPAmelanin $)-\mathrm{Cu}(\mathrm{II})$, [(DOPA-melanin)-kanamycin]-Cu(II), [(DOPA-melanin)-Cu(II)]-kanamycin. The concentration of kanamycin was equal to $1 \times 10^{-3} \mathrm{M}$, and copper(II) chloride solution was in the range $1 \times 10^{-5}-1 \times 10^{-3} \mathrm{M}$.

\section{Method}

EPR spectra of DOPA-melanin complexes were recorded at room temperature by the use of EPR spectrometer SE/X RADIOPAN, Poznań, POLAND working at frequency $9.4 \mathrm{~Hz}$. Modulation of magnetic field was equal to $100 \mathrm{kHz}$. The meter MCM EPRAD-Poznań, POLAND, was used for measurement of frequency of microwave radiation. EPR spectra were recorded as the first derivative of energy absorption at the attenuation from the range $20-0 \mathrm{~dB}$ which corresponds to value of microwave power from the range $0.7-70 \mathrm{~mW}$. Microwave power was registered in arbitrary units as $P_{0} / P$ according to the formula:

$$
\text { Attenuation }[\mathrm{dB}]=10 \log \left(P_{0} / P\right) \text {, }
$$

where $P_{0}$ - microwave power produced by klystron, $P$ microwave power used during measurement. Linewidth of EPR spectrum is defined as the distance from peak to peak on the first derivative of energy absorption.

\section{Results and discussion}

Influence of microwave power on EPR parameters of melanin radical and copper(II) ions in DOPA-melanin complexes was analyzed. Adding of drug into melanin causes the increase of amplitude $A$ of EPR signal. Drugs 
cause higher concentration of melanin paramagnetic centers $[11,12]$. Intensity $I$ of EPR line is proportional to concentration of paramagnetic centers in sample and intensity $I$ is proportional to amplitude $A$ and for symmetric EPR line we can write

$$
I=\left(A_{\mathrm{s}} / A_{\mathrm{r}} m_{\mathrm{s}}\right)\left(\Delta B_{\mathrm{pp}}\right)^{2},
$$

where $A_{\mathrm{s}}$ - amplitude of EPR signal of melanin radicals, $A_{\mathrm{r}}$ - amplitude of EPR signal of ruby crystal used as the inner reference, $m_{\mathrm{s}}$ - mass of the sample, $\Delta B_{\mathrm{pp}}$ - linewidth peak to peak. Samples with different order of adding of drug and metal ions were tested. A component used (drug or $\mathrm{Cu}(\mathrm{II})$ ions) added first into melanin during preparation of samples blocades bonding sites in melanin for second component.

All recorded EPR signal for melanin radical saturate with increase of microwave power (Fig. 1). Melanin paramagnetic centers are characterized by long spin-lattice relaxation time $T_{1}$. $\mathrm{Cu}(\mathrm{II})$ ions bonded with melanin cause shifting of effect of microwave saturation towards higher value of microwave power (shortening of $T_{1}$ ). Our results confirm and complement earlier works in this field [11-13].

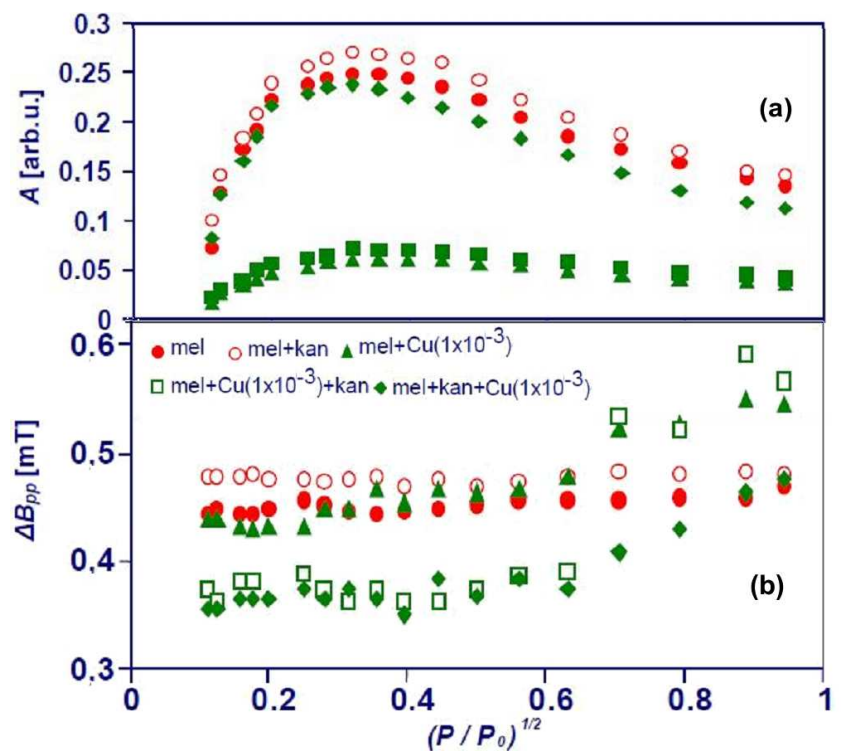

Fig. 1. Influence of microwave power on amplitude $A$ (a) and linewidth $\Delta B_{\mathrm{pp}}$ (b) of EPR signal of melanin radicals in DOPA-melanin and in its complexes with $\mathrm{Cu}$ (II) ions and kanamycin. Concentrations of metal ions are given in the figure.

For all samples linewidth of EPR signal was discussed. The dependence of linewidth versus microwave power for chosen complexes is presented in Fig. 1 and 2. Linewidth of parent sample and melanin-kanamycin complex is nearly the same (Fig. 1). Microwave saturation of EPR signal in complexes with only copper(II) ions is shown in Fig. 2. The phenomenon of microwave saturation is shifted to higher values of microwave power in comparison to samples delineated in Fig. 1. Shortening of re-

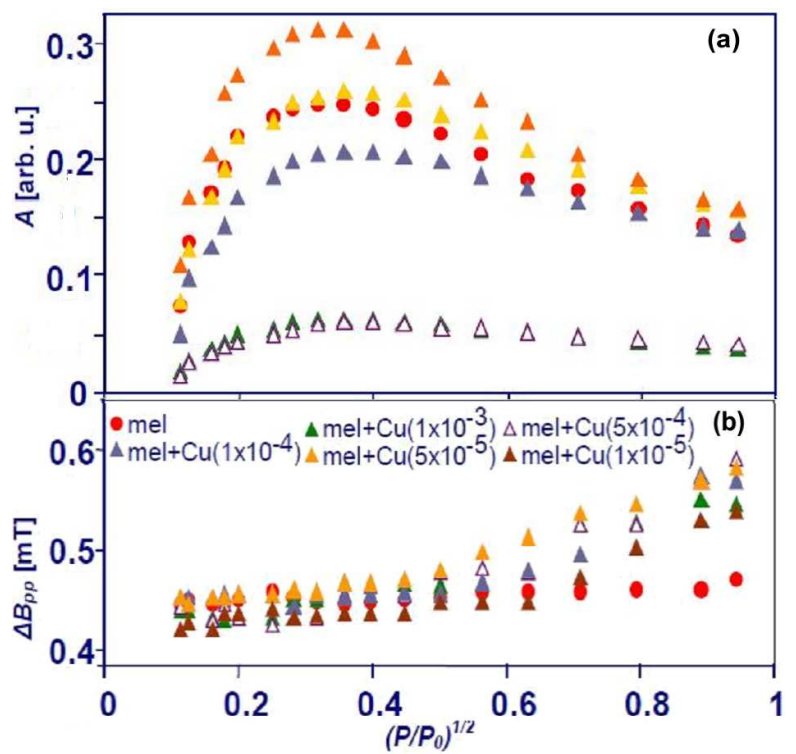

Fig. 2. Influence of microwave power on amplitude $A$ (a) and linewidth $\Delta B_{\mathrm{pp}}$ (b) of EPR signal of melanin radicals in DOPA-melanin and in its complexes with $\mathrm{Cu}$ (II) ions. Concentrations of metal ions are given in the figure.

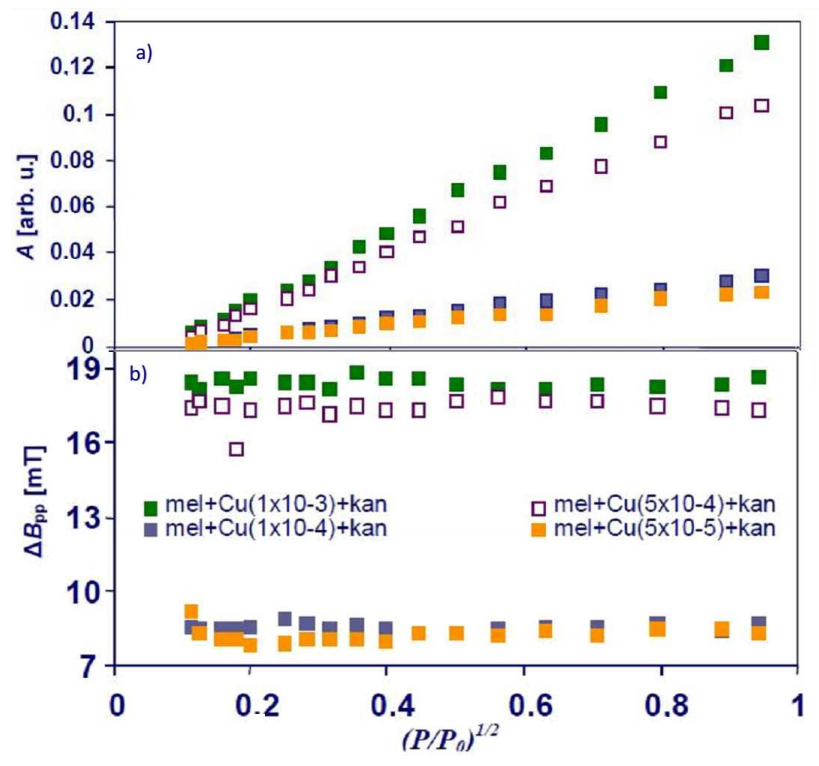

Fig. 3. Influence of microwave power on amplitude $A$ (a) and linewidth $\Delta B_{\mathrm{pp}}$ (b) of EPR signal of $\mathrm{Cu}$ (II) ions in DOPA-melanin complexes with $\mathrm{Cu}(\mathrm{II})$ ions and kanamycin. Concentrations of metal ions are given in the figure.

laxation time $T_{1}$ is better visible for samples with lower concentration of $\mathrm{Cu}(\mathrm{II})$ ions (Fig. 2). Linewidth of EPR signal of melanin radical measured for melanin- $\mathrm{Cu}(\mathrm{II})$ complexes is higher with growing of microwave power (Fig. 2). The same situation is observed for melanin$\mathrm{Cu}$ (II)-kanamycin complexes (Fig. 1). The highest val- 
ues of linewidth were measured for complexes with the lowest concentration of $\mathrm{Cu}(\mathrm{II})$ ions.

The decrease of amplitude and increase of linewidth of EPR melanin signal take place in all range of used concentration of metal ions. Collected results obtained by continuous wave saturation of EPR signal showed that EPR signal of melanin radicals are homogeneously bordered (amplitudes saturated and linewidth increased for higher values of microwave power). Lowering of amplitude of EPR signal with increase of microwave powers was promoted by spins from higher energy level which are not able to return on lower energy level in proper time. Microwave saturation did not exist for paramagnetic $\mathrm{Cu}$ (II) ions in melanin complexes $[11,14] . \mathrm{Cu}(\mathrm{II})$ ions are characterized by short spin-lattice relaxation time $[11,13]$ and in used range of microwave power microwave saturation is not noticed. For lower concentration of copper(II) ions, small amount of ions bonded with melanin $[9,11,13]$ and EPR signal of them is not recorded. Higher values of amplitudes of $\mathrm{Cu}(\mathrm{II})$ signal appeared with increase of concentration of metal ions (Fig. 3) (in this place we chose for presentation melanin-kanamycin$\mathrm{Cu}$ (II) complexes). Linewidth of $\mathrm{Cu}(\mathrm{II})$ signal is constant with change of microwave power (Fig. 3). Amplitude of EPR signal of $\mathrm{Cu}(\mathrm{II})$ ions is the highest for melanin$\mathrm{Cu}$ (II) and the lowest for melanin-kanamycin- $\mathrm{Cu}$ (II) complexes which is confirmation of different amount of metal ions bonded with melanin. Realized study of melanin and its complexes with kanamycin and $\mathrm{Cu}$ (II) ions by continuous microwave saturation showed dissimilar nature of melanin paramagnetic centers and $\mathrm{Cu}(\mathrm{II})$ ions. $\mathrm{Cu}(\mathrm{II})$ ions added into melanin prompt to shortening of spin-lattice relaxation time $T_{1}$. Kanamycin and another drug do not change the time $T_{1}[11,12,14]$. EPR signal recorded for DOPA-melanin and next for melanin-kanamycin complex saturate at the similar microwave power.

\section{Conclusions}

The analysis of influence of microwave power on EPR signal of studied samples showed that slow spin-lattice relaxation processes exists in melanin radical system and fast processes are typical for $\mathrm{Cu}(\mathrm{II})$ ions system. Microwave saturation is only observed for melanin paramagnetic centers (indol-5,6-semiquinone groups). Microwave saturation is not observed for $\mathrm{Cu}$ (II) ions using microwave power range $(0.7-70 \mathrm{~mW})$.

\section{References}

[1] K. Wakamatsu, S. Ito, Pigment Cell Res. 15, 174 (2002).

[2] B.S. Larson, Pigment Cell Res. 6, 127 (1993).

[3] U. Mars, B.S. Larson, Pigment Cell Res. 12, 266 (1999).

[4] K.B. Stepień, J.P. Dworzański, S. Imielski, T. Wilczok, J. Anal. Appl. Pyrol. 9, 297 (1986).

[5] A.A. Chiodo, P.W. Abberti, Eur. Arch. Otorhinolaryngol. 251, 375 (1994).

[6] J. Marais, J.A. Rutka, Clin. Otolaryngol. 23, 360 (1998).

[7] C.C. Felix, J.S. Hyde, T. Sarna, R.C. Sealy, J. Am. Chem. Soc. 100, 3922 (1978).

[8] L. Najder-Kozdrowska, B. Pilawa, E. Buszman, A.B. Więckowski, L. Świątkowska, D. Wrześniok, W. Wojtowicz, Acta Phys. Pol. A 118, 613 (2010).

[9] L. Najder-Kozdrowska, B. Pilawa, E. Buszman, D. Wrześniok, A.B. Więckowski, Spectroscopy 25, 197 (2011).

[10] F. Bins, R.F. Chapman, N.C. Robson, G.A. Swan, A. Waggot, J. Chem. Soc., 1128 (1970).

[11] B. Pilawa, M. Latocha, E. Buszman, T. Wilczok, Appl. Magn. Reson. 25, 105 (2003).

[12] B. Pilawa, E. Buszman, D. Wrześniok, M. Latocha, T. Wilczok, Appl. Magn. Reson. 23, 181 (2002).

[13] L. Najder-Kozdrowska, B. Pilawa, A.B. Więckowski, E. Buszman, D. Wrześniok, Appl. Magn. Reson. 36 , 81 (2009).

[14] E. Chodurek, B. Pilawa, A. Dzierżęga-Lęcznar, S. Kurkiewicz, L. Kwiatkowska, T. Wilczok, J. Anal. Appl. Pyrol. 70, 43 (2003). 